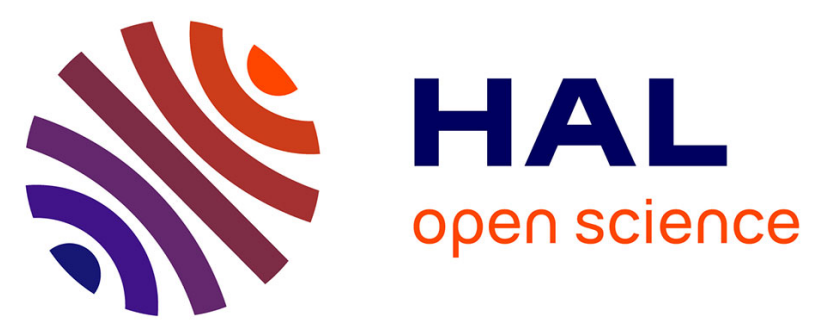

\title{
Asymmetric responses of ecosystem productivity to rainfall anomalies vary inversely with mean annual rainfall over the conterminous United States
}

Amen Al-yaari, Wigneron J.-P., Philippe Ciais, Markus Reichstein, Ashley Ballantyne, Jerome Ogée, Agnès Ducharne, Jennifer J Swenson, Frédéric Frappart, Lei Fan, et al.

\section{To cite this version:}

Amen Al-yaari, Wigneron J.-P., Philippe Ciais, Markus Reichstein, Ashley Ballantyne, et al.. Asymmetric responses of ecosystem productivity to rainfall anomalies vary inversely with mean annual rainfall over the conterminous United States. Global Change Biology, 2020, 26 (12), pp.6959 - 6973. 10.1111/gcb.15345 . hal-03376713

\section{HAL Id: hal-03376713 \\ https://hal.science/hal-03376713}

Submitted on 15 Oct 2021

HAL is a multi-disciplinary open access archive for the deposit and dissemination of scientific research documents, whether they are published or not. The documents may come from teaching and research institutions in France or abroad, or from public or private research centers.
L'archive ouverte pluridisciplinaire HAL, est destinée au dépôt et à la diffusion de documents scientifiques de niveau recherche, publiés ou non, émanant des établissements d'enseignement et de recherche français ou étrangers, des laboratoires publics ou privés. 


\title{
Asymmetric responses of ecosystem productivity to rainfall anomalies vary inversely with mean annual rainfall over the conterminous United States
}

\author{
Amen Al-Yaari ${ }^{1}$ (D) | Jean-Pierre Wigneron ${ }^{2}$ (D) | Philippe Ciais ${ }^{3}$ | Markus Reichstein ${ }^{4}$ | \\ Ashley Ballantyne $^{5}$ | Jerome Ogée ${ }^{2}$ (D) | Agnès Ducharne ${ }^{1}$ | Jennifer J.Swenson ${ }^{6}$ | \\ Frédéric Frappart $^{7}$ | Lei Fan ${ }^{8}$ | Lisa Wingate ${ }^{2}$ | Xiaojun Li ${ }^{2}$ | Koen Hufkens ${ }^{9}$ | \\ Alan K. Knapp ${ }^{10}$
}

${ }^{1}$ Sorbonne Université, UMR 7619 METIS, Paris, France

${ }^{2}$ INRAE, Université de Bordeaux, UMR1391 ISPA, Villenave d'Ornon, France

${ }^{3}$ Laboratoire des Sciences du Climat et de l'Environnement, IPSL, Gif-sur-Yvette, France

${ }^{4}$ Department of Biogeochemical Integration, Max Planck Institute for Biogeochemistry, Jena, Germany

${ }^{5}$ W.A. Franke College of Forestry \& Conservation Global Climate and Ecology Laboratory, University of Montana, Missoula, MT, USA

${ }^{6}$ Nicholas School of the Environment, Duke University, Durham, NC, USA

${ }^{7}$ LEGOS, Université de Toulouse, CNES, CNRS, IRD, Toulouse, France

${ }^{8}$ School of Geographical Sciences, Nanjing University of Information Science and Technology, Nanjing, China

${ }^{9}$ Faculty of Bioscience Engineering, Ghent University, Ghent, Belgium

${ }^{10}$ Department of Biology and Graduate Degree Program in Ecology, Colorado State University, Fort Collins, CO, USA

\section{Correspondence}

Amen Al-Yaari, Sorbonne Université, UMR 7619 METIS, Case 105, 4 Place Jussieu, Paris F-75005, France.

Email: amen.al-yaari@sorbonne-universite.fr

Jean-Pierre Wigneron, INRAE, UMR1391 ISPA, Université de Bordeaux, F-33140 Villenave d'Ornon, France.

Email: jean-pierre.wigneron@inrae.fr

Funding information

Centre national d'études spatiales

\begin{abstract}
The CONterminous United States (CONUS) presents a large range of climate conditions and biomes where terrestrial primary productivity and its inter-annual variability are controlled regionally by rainfall and/or temperature. Here, the response of ecosystem productivity to those climate variables was investigated across different biomes from 2010 to 2018 using three climate datasets of precipitation, air temperature or drought severity, combined with several proxies of ecosystem productivity: a remote sensing product of aboveground biomass, an net primary productivity (NPP) remote sensing product, an NPP model-based product and four gross primary productivity products. We used an asymmetry index (AI) where positive $\mathrm{Al}$ indicates a greater increase of ecosystem productivity in wet years compared to the decline in dry years, and negative Al indicates a greater decline of ecosystem productivity in dry years compared to the increase in wet years. We found consistent spatial patterns of Al across the CONUS for the different products, with negative asymmetries over the Great Plains and positive asymmetries over the southwestern CONUS. Shrubs and, to a lesser extent, evergreen forests show a persistent positive asymmetry, whilst (natural) grasslands appear to have transitioned from positive to negative anomalies during the last decade. The general tendency of dominant negative asymmetry response for ecosystem productivity across the CONUS appears to be influenced by the negative asymmetry of precipitation anomalies. Al was found to be a function of mean rainfall: more positive Als were found in dry areas where plants are adapted to drought and take advantage of rainfall pulses, and more negative Als were found in wet areas, with a threshold delineating the two regimes corresponding to a mean annual rainfall of $200-400 \mathrm{~mm} /$ year.
\end{abstract}

KEYWORDS

asymmetry, biomass, ecosystem productivity, GPP, NPP 


\section{1 | INTRODUCTION}

Terrestrial ecosystems control the inter-annual variability of the global carbon budget (Bousquet et al., 2000; Le Quéré et al., 2018). Although the tropics dominate the strength and variability of the terrestrial carbon sink (Piao et al., 2020), semiarid regions are thought to be disproportionately important in controlling the inter-annual and decadal variability in the global carbon cycle (Ahlström et al., 2015), and in particular climate extremes (Reichstein et al., 2013). The global and regional pattern distribution of $C$ sinks is reflected in the biomass of ecosystems and their productivity which is influenced by inter-annual variations in climate caused by abiotic factors (climate-induced disturbances and soil properties) and biotic ones (biodiversity, plant traits, herbivory, and pest outbreaks; Asner et al., 2018; Fahey \& Knapp, 2007; Hsu et al., 2012).

The CONterminous United States (CONUS) is comprised of diverse climate conditions and ecosystems with productivity and its variability being mostly controlled by either precipitation or temperature that varies strongly between regions (e.g., Liu et al., 2019). For example, during the period 1991-2012, precipitation increased overall in the CONUS, but trends vary regionally with strong and moderate drying measured in the Southwest (epicenter in Arizona) and Southeast, respectively (Williams et al., 2020), whilst rainfall has increased in the North Great Plains and the Midwest. The regional responses of ecosystem productivity to wet and dry years have previously been investigated over the CONUS using annual aboveground net primary productivity (ANPP) data from sitebased observations (Hsu et al., 2012; Knapp et al., 2017; Knapp \& Smith, 2001; Unger \& Jongen, 2015; Wilcox et al., 2017; Wu et al., 2018; Wu et al., 2011). Knapp and Smith (2001) were the first to observe a generally positive asymmetry in the ANPP in response to rainfall anomalies across different long-term ecological sites, that is, a relatively greater increase in ANPP anomalies during wet years compared with the relative decreases in ANPP anomalies during dry years. Positive asymmetry was greatest in grasslands and Knapp and Smith (2001) have attributed this response to drought tolerance or resistance mechanisms at the ecosystem scale that buffered declines of ANPP in dry years. In contrast, a number of recent studies have observed negative asymmetry between ANPP and precipitation at other sites, mainly grasslands (Bai et al., 2008; Yang et al., 2008). Thus, a lack of consistent and continuous information at large (regional or continental) scales persists regarding the sign of asymmetry and consequently our understanding of the response of productivity to inter-annual rainfall variations. In addition, it is not clear whether the sign of the asymmetry is susceptible to variations over the long term in response to changes in environmental conditions or during extremely dry years that could cause vegetation stress to exceed thresholds in drought-buffering mechanisms.

Here, we evaluated the asymmetry response of vegetation productivity to rainfall across different CONUS biomes (Figure S1) over the period 2010 to 2018 . This period contained three of the hottest years (2012, 2016, and 2017) on record (NOAA, 2018) for the U.S. and a very wet year (2015). In particular, 2012 stood out as the hottest year during this period (Melillo et al., 2014) concurrent with a severe summer mega-drought over the Great Plains and the Midwest Corn Belt (Hoerling et al., 2013; Wolf et al., 2016). Thus, the period analyzed in this study includes climate extremes of greater magnitude than previously observed by Knapp and Smith (2001).

Furthermore, the 2010-2018 period also coincides with the availability of new L-band vegetation optical depth (L-VOD) data from the soil moisture and ocean salinity (SMOS) satellite mission in the SMOS-IC version (Li et al., 2020). We have recently demonstrated that L-VOD is an indicator of the spatial and temporal dynamics of aboveground biomass ( $A G B$ in $\mathrm{Mg} / \mathrm{ha}$ ), based on its strong linear relation to biomass (Brandt et al., 2018; Fan et al., 2019; Wigneron et al., 2020). Thus, here we now establish a specific relationship that links mean SMOS-IC L-VOD to a spatially explicit map of AGB (Saatchi et al., 2011) across the CONUS (Figure S2). This L-VODderived $A G B$ product was then used to estimate annual changes in AGB (i.e., ANPP) at a spatial resolution of $25 \mathrm{~km}$.

Alongside the SMOS-derived time varying gridded AGB datasets, we used the MODIS-NPP product from (Zhao et al., 2005), TRENDY (Trends in net land-atmosphere carbon exchange over the period 1980-2010) model outputs for NPP and gross primary productivity (GPP) simulations (Le Quéré et al., 2018; Sitch et al., 2008), and four additional data-driven GPP products derived from eddy covariance flux tower measurements and satellite observations (Jiang \& Ryu, 2016; Jung et al., 2017; Stocker et al., 2019).

We combined these datastreams to address the following questions: (a) What are the responses of primary productivity to extreme precipitation anomalies during the recent decades over the CONUS? (b) Does the positive asymmetry evidenced from the site-based approach of Knapp and Smith (2001) still hold across large spatial scales (CONUS) during the last decade, in light of the general increasing trend in warmer and dryer/wetter periods observed in 2000-2018?

\section{2 | MATERIALS AND METHODS}

\subsection{Datasets}

\subsection{1 | Ecosystem productivity}

Different datasets evaluating vegetation productivity in terms of biomass change, GPP and ANPP were aggregated to yearly values at a spatial resolution of $0.5^{\circ}$ and used to compute the asymmetry index (Al) over the CONUS:

I The SMOS satellite was launched in 2009 to measure brightness temperature (TB) in the L-band frequency region $(\sim 1.4 \mathrm{GHz})$ in $\mathrm{H}$ and $\mathrm{V}$ polarizations with a range of incidence angles from $0^{\circ}$ to $60^{\circ}$ (AI-Yaari et al., 2019; Kerr et al., 2016). The SMOS-IC vegetation optical depth (SMOS L-VOD) product is derived from the SMOS satellite observations using the L-MEB (L-band Microwave Emission of the Biosphere) model (Wigneron et al., 2007). More 
details about the SMOS-IC algorithm and product can be found in Fernandez-Moran et al. (2017). SMOS-IC L-VOD data from both ascending and descending orbits from 2010 to 2018 were combined and used in this study (https://ib.remote-sensing.inrae.fr/). To select high-quality data, SMOS-IC L-VOD values with a root mean squared difference between modeled and observed TB larger than $8 \mathrm{~K}$ were screened out (Li et al., 2020). The CONUS region is ideal for SMOS L-VOD applications because the product is of high quality over this area due to the low negative impact of Radio Frequency Interference on the SMOS L-VOD retrievals (Oliva et al., 2016). The SMOS-IC L-VOD product has been shown to be a promising tool to monitor AGB dynamics (Brandt et al., 2018; Rodríguez-Fernández et al., 2018). Here, over the CONUS, the mean SMOS-IC L-VOD (2014) and Saatchi AGB (Mg/ha) map (Saatchi et al., 2011) were found to be strongly and linearly correlated $(R=.92$; see Figure $\mathrm{S} 2)$. The latter relationship was used to compute a proxy of AGB from L-VOD in this study. However, it should be noted that the underlying relationship between $A B G$ and VOD could be nonlinear, with VOD saturating at high biomass and very sensitive at low biomass. As we are interested in the ecosystem productivity, the AGB difference ( $\triangle \mathrm{AGB}$ ) between the maximum (during the growing season) and minimum (during winter) within a year was computed and considered as proxy of ANPP. For vegetation such as grasslands and crops, $\triangle \mathrm{AGB} \approx \mathrm{ANPP}$, but for forests the contribution from changes in mortality should be included in theory;

II annual net primary productivity (NPP) generated from the MODIS algorithm (MOD17), with a spatial resolution of $250 \mathrm{~m}$ was used. This algorithm is based on the Collection 4.5 MODIS GPP (MOD17) data, available from the University of Montana's Numerical Terradynamic Simulation Group on ftp site (http:// files.ntsg.umt.edu/data/NTSG_Products/MOD17/MODIS_250/ modis-250-npp/; Zhao et al., 2005) with a temporal coverage from 2001 to 2018 (Robinson et al., 2018). The MOD17 algorithm estimates GPP using a light use efficiency (LUE) approach forced by MODIS fraction of photosynthetically active radiation and leaf area index, as well as surface air temperature, incoming solar radiation, and vapor pressure deficit derived from a meteorology dataset from the NASA Global Modelling and Assimilation Office and the NCEP/NCAR Reanalysis II, and land cover classes from the MCD12Q1 data product. It should be noted that the MOD17 NPP product does not account for the soil moisture stress explicitly;

III the GPP product from the Prentice model (i.e., P-model) simulations that have been corrected using empirical soil moisture stress functions (Stocker et al., 2019; Prentice-GPP). The P-model is another LUE model, where GPP is simulated per unit of absorbed photosynthetically active radiation from elevation, latitude, temperature, fractional cloud cover and precipitation (Wang et al., 2017). Data are provided as NetCDF files at a spatial resolution of $0.5^{\circ}$ and daily temporal resolution and can be freely downloaded from https://zenodo.org/record/1423484. Unlike the MOD17 NPP, the P-model GPP accounts for soil moisture deficit explicitly;

IV the machine learning approaches for upscaling biosphereatmosphere fluxes from FLUXNET observations to global scale (FLUXCOM)-GPP product (F-GPP) estimated upscaled FLUXNET net ecosystem $\mathrm{CO}_{2}$ exchange observations using meteorological data (CRUNCEP V6), remotely sensed data and various machine learning algorithms (Jung et al., 2017). Soil moisture in the FLUXCOM approach is rather a proxy for plant available water, and is termed here as water availability index. It is calculated with a two-layer cascading bucket model with precipitation, net radiation, and fraction of absorbed photosynthetically active radiation (fPAR) as inputs. For more details, see Jung et al. $(2019,2020)$ as well as Tramontana et al. (2016). The F-GPP product is provided as NetCDF files at a spatial resolution of $0.5^{\circ}$ and daily temporal resolution for the period 1950-2017 and can be freely downloaded from https://www.bgc-jena.mpg.de/geodb/projects/Home.php;

$\checkmark$ the Breathing Earth System Simulator (BESS) GPP (B-GPP) product that is produced from a process-based model that couples radiative transfer between the canopy and atmosphere by simulating evapotranspiration and photosynthesis using multiple satellite remote sensing datasets (Jiang \& Ryu, 2016). For BESS, soil moisture is not directly considered as it is not forcing the model. Soil moisture effects on the stomatal conductance were considered via the Ball-Berry formulation (Ryu et al., 2011). The BESSGPP product is provided as NetCDF files at a spatial resolution of $0.5^{\circ}$ and monthly temporal resolution for the period 2001-2015 (http://environment.snu.ac.kr/bess/);

$\mathrm{VI}$ the latest available version (Trendy-v7) of the ensemble of eight Trendy ecosystem models and land surface models over 2010-2017 was used in this study (Le Quéré et al., 2018; Sitch et al., 2015). We used the S3 simulations where variable $\mathrm{CO}_{2}$, climate and land use (using updated annual land use and land cover change maps to 2017) were prescribed to all models. The TRENDY model simulations presented here thus represent carbon cycle responses of the biophysical land surface to climate and $\mathrm{CO} 2$ change, including emissions caused by land use change. Simulations are forced with climate information from CRUJRA-55. We have used the CABLE-POP, ISAM, LPJ, LPX-Bern, ORCHIDEE, O-CN, DLEM, and LPJ-GUESS models, which can be freely downloaded from trendy-v7@trendy.ex.ac.uk; and

VII the in situ FLUXNET2015 GPP from multiple sites, which is the latest release of the international network FLUXNET (Baldocchi et al., 2001) of ecosystem net $\mathrm{CO}_{2}$ exchange data measured with eddy covariance techniques. This product consists of a harmonized dataset from international projects, regional networks and field-sites of research institutes, including postprocessed GPP estimates from the direct measurements of net ecosystem $\mathrm{CO}_{2}$ exchange. The FLUXNET2015 daily GPP estimates were obtained from http://fluxnet.fluxdata.org/data/fluxnet2015-datas et/. We considered all GPP data based on both night-time and day-time partitioning methods of the net ecosystem $\mathrm{CO}_{2}$ exchange: GPP_NT_VUT_REF, GPP_NT_VUT_25, GPP_NT_VUT_50 
and GPP_NT_VUT_75 in the FLUXNET 2015 dataset. Negative GPP values were filtered out.

\subsection{2 | Climate variables}

Different climate datasets, aggregated to the annual time step, were used to make the results more robust and to examine the uncertainties:

I the Climate Prediction Centre (CPC) Global Unified Gauge-Based Analysis of Daily Precipitation that is produced by NOAA and is a global land-only product obtained based on a gauge-based analysis (gauge reports from over 30,000 stations) with a daily time step (Chen et al., 2008; Xie et al., 2007). The quality of CPC data has been evaluated against historical records and measurements at nearby stations, concurrent radar/satellite observations, as well as numerical model forecasts. The global CPC daily product is constructed at a spatial resolution of $0.125^{\circ}$ but is released at a spatial resolution of $0.5^{\circ}$, with a temporal coverage of 1979present (see https://www.esrl.noaa.gov/psd/data/gridded/data. cpc.globalprecip.html for data and more details). The CPC daily product is free and made available online by the NOAA/OAR/ ESRL PSD, Boulder, Colorado, USA (https://www.esrl.noaa.gov/ $\mathrm{psd} /$ ). In this study, the daily observed gauge-derived CPC precipitation over 2010-2018 was summed for the period Jan-Dec for each year;

II the Gridded surface meteorological dataset (GRIDMET) surface meteorological data of daily maximum temperature, minimum temperature, precipitation accumulation, and 10-day Palmer Drought Severity Index (PDSI) with a spatial resolution of $\sim 4 \mathrm{~km}$ covering the CONUS over the period 1979-2018. PDSI is a widely used index of integrated water supply and demand anomalies estimated using precipitation and potential evapotranspiration (PET). The GRIDMET data combines gridded climate data from the Parameter elevation Regressions on Independent Slopes Model (Abatzoglou, 2013), which can be freely downloaded from http://www.climatologylab.org/gridmet.html; and

III the CRU TS Version 4 (Climatic Research Unit gridded Time Series) monthly precipitation and PET dataset. The CRU datasets are provided at a spatial resolution of $0.5^{\circ}$ in NetCDF format that cover the period 1901-2018 (Harris et al., 2020) and comprise over 10,000 meteorological stations worldwide; they can be downloaded from http://www.cru.uea.ac.uk/data.

\subsection{3 | Other datasets}

\section{Land cover map}

We used the USGS National Land Cover Dataset (NLCD) 2011 (Wickham et al., 2014) which is based on Landsat and ancillary data sources (e.g., topography, census and agricultural statistics, soil characteristics, wetlands, etc.). The NLCD map is provided at a spatial resolution of $30 \mathrm{~m}$ and can be downloaded from https:// catalog.data.gov/dataset/nlcd-2011-land-cover-2011-editionamended-2014-national-geospatial-data-asset-ngda-land-use-la. The CONUS vegetation is stratified into six land cover classes: deciduous forest, evergreen forest, shrubs, grasslands, pasture, and crops, corresponding with different climate regimes (see Figure S1).

\section{Vegetation health index}

The vegetation health index (VHI) has been widely used for drought and vegetation activity monitoring (Bento et al., 2018; Pei et al., 2018). VHI represents the overall vegetation health that is computed as follows (Kogan, 2001):

$$
\mathrm{VHI}=0.5 * \mathrm{VCI}+0.5 * \mathrm{TCl}
$$

where $\mathrm{VCl}$ is the Vegetative Condition Index, which is related to the long-term minimum and maximum Normalized Difference Vegetation Index (NDVI):

$$
\mathrm{VCI}=100 * \frac{\mathrm{NDVI}_{\max }-\mathrm{NDVI}}{\mathrm{NDVI}_{\max }-\mathrm{NDVI}_{\min }}
$$

where $\mathrm{TCl}$ is the Temperature Condition Index, which represents the relative change in thermal condition and is computed from the minimum and maximum of TB values that are obtained from the thermal band of NOAA-AVHRR:

$$
\mathrm{TCl}=100 * \frac{\mathrm{BT}_{\max }-\mathrm{BT}}{\mathrm{BT}_{\max }-\mathrm{BT}_{\min }} .
$$

$\mathrm{VCl}$ characterizes vegetation moisture stress and $\mathrm{TCl}$ characterizes the thermal condition of vegetation. $\mathrm{VHI}$ datasets were provided at a spatial resolution of $16 \mathrm{~km}$ and can be freely downloaded from https://www.star.nesdis.noaa.gov/smcd/emb/vci/ VH/vh_ftp.php.

\section{Maximum rooting depth}

Ecosystem resilience to drought is affected by plant rooting depth (Fan et al., 2017). Therefore, we used the modeled maximum depth of root uptake averaged over 10 years (2004-2013) reported in Fan et al. (2017) to help interpret the obtained results. It was estimated based on inverse modeling of observed productivity and water availability atmosphere at $30^{\prime \prime}(1 \mathrm{~km})$ and can be downloaded from https://wci.earth2observe.eu/thredds/catalog/usc/root-depth/catal og.html.

\section{2 | Methods}

\subsubsection{Asymmetry index}

The relative positive pulses (or gains) and negative pulses (or declines), widely used as asymmetric indices, were computed as follows (Knapp \& Smith, 2001): 


$$
\text { Positive pulse }=\frac{\max (\mathrm{var})-\overline{\mathrm{var}}}{|\overline{\mathrm{var}}|}
$$

Negative decline $=\frac{\overline{\operatorname{var}}-\min (\text { var })}{|\overline{\operatorname{var}}|}$,

where var is the yearly value of SMOS L-VOD, GPP, NPP, or precipitation; max and min are the maximum and minimum values over the whole data record, and the overbar represents the overall mean of the yearly values. Positive pulses and negative declines represent, respectively, the relative productivity gains and declines in wet and dry years, namely increase or decrease in productivity relative to the mean annual value of productivity. In this study, positive pulses will be referred simply to as pulses and negative declines to as declines.

In order to study the asymmetry of the inter-annual biomass productivity response to precipitation, we computed the Al following (Wu et al., 2018):

$$
\mathrm{Al}=\text { Pulse }- \text { Decline }
$$

Al greater than 0 indicates a positive asymmetry (i.e., a greater gain of productivity in wet years than decline in dry years) and $\mathrm{Al}$ lower than 0 indicates a negative asymmetry (i.e., there is a greater decline of productivity in dry years than gain in wet years). Running means of the Al of inter-annual products at the biome scale using a temporal window of $9,11,13,15$ years, etc. up to the entire datasets were computed.

\subsection{2 | Skewness}

We also computed the skewness of the different datasets according to Joanes and Gill (1998):

$$
S=\frac{m_{3}}{\left(m_{2}\right)^{3 / 2}}
$$

where $m_{2}$ and $m_{3}$ are the second and third central moments (or moment about the mean). While a positive skewness indicates that the data distribution is skewed to right, negative skewness indicates that the data distribution is skewed to the left. Skewness is related to $\mathrm{Al}$, that is a positive value should broadly correspond to positive $\mathrm{Al}$ and vice versa.

\subsection{3 | Variable importance}

The asymmetry of productivity may reflect either asymmetry of precipitation anomalies, asymmetry of the biotic response, or both. Large-scale spatial gradients of annual precipitation control the distribution of biomes and life zones around the globe (Holdridge, 1947). Annual precipitation also limits plant productivity over most of the globe and controls biomass (Ahlström et al., 2015; Huxman, Smith, et al., 2004; Huxman, Snyder, et al., 2004). Precipitation is a simple measure of ecosystem water availability that is accurately estimated across the CONUS (e.g., the NOAA CPC unified gauge-based data; Chen et al., 2008), and there are several lines of evidence for strong relationships of precipitation with ecosystem production in this region (Knapp et al., 2017; Knapp \& Smith, 2001). We, therefore, considered some precipitation-related variables and a biotic variable (Knapp \& Smith, 2001) to explain the spatial patterns of Al. These variables are the asymmetry of rainfall anomalies (AiPR), the annual precipitation variability (CVPR; computed as the ratio of the $S D$ to the mean), the annual precipitation to PET ratio (RATio) which is the inverse of the Budyko aridity index) and the mean annual precipitation (MeanPR). In addition, we considered one biotic variable, the ecosystem productivity potential (MaxNPP; defined by the maximum values of NPP). We used a Random Forest (RF) model (Breiman, 2001; Liaw \& Wiener, 2002) to determine the most important variables, with the highest explanatory power of Al, that may be considered as drivers of the Al. For this purpose, we created maps of AiPR, MaxNPP, CVPR, MeanPR, and RATio and we applied the RF algorithm to explain the spatial patterns of the Al with these predictors. More specifically, RF was first applied using all pixels of the created maps (i.e., across the whole CONUS) and then applied only per each biome.

\section{3 | RESULTS}

\subsection{Spatial patterns of the productivity asymmetry}

We evaluated the asymmetry of productivity over the CONUS using the $\mathrm{Al}$ and skewness. The spatial distribution of the $\mathrm{Al}$ response is broadly coherent among the different GPP proxies (observations and simulations), with more pronounced negative $\mathrm{Al}$ values observed over the central plains, a transitional zone between arid and mesic eastern regions (Figure 1). Conversely, positive Al of GPP values were found over the Western and Southwestern CONUS in all proxies, with no clear asymmetry in the East. We also observed that SMOS-VOD and both NPP products exhibited a larger area of negative Al than any of the GPP datasets. The spatial patterns of the Al values were similar to those of the skewness patterns (Figure S3) except in the East, and thus we will focus on the Al results in the subsequent analysis.

\subsection{Biome specific asymmetry}

Across six biomes, deciduous forest, evergreen forest, shrubs, grasslands, pasture, and crops (classified according to the U. S. Geological Survey, 2011), the mean Al values of productivity and AGB were mainly negative (i.e., maximum decline was greater than maximum pulse) as seen in Figure 2. The SMOS L-VOD, that accounts for mortality, Al values were negative on average over all biomes while the $\mathrm{Al}$ indices of MODIS and TRENDY NPP were positive for evergreen 


\section{SMOS-VOD}

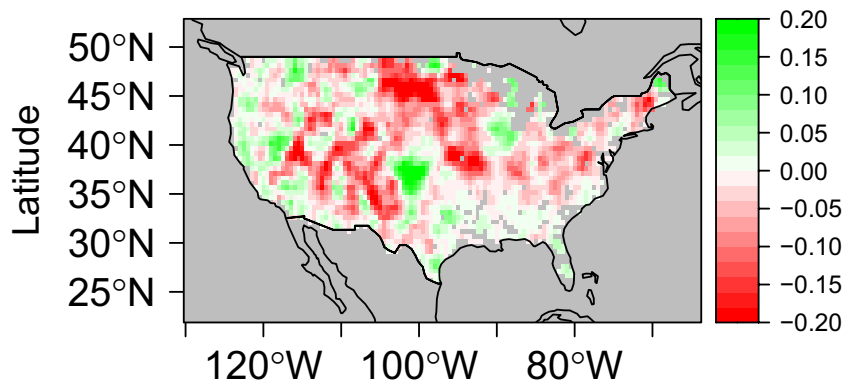

MODIS-NPP

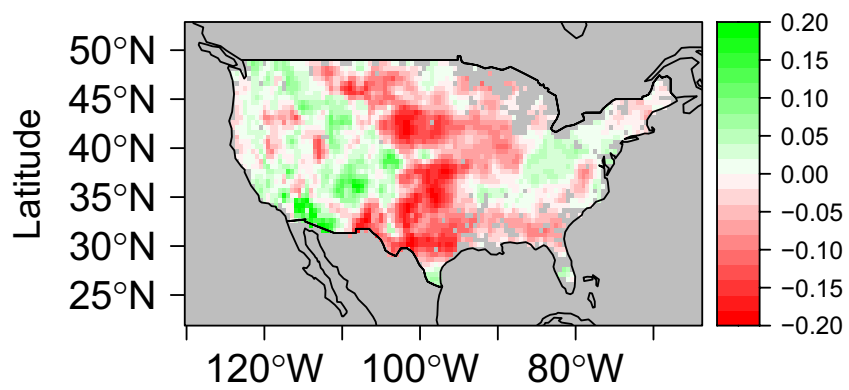

Trendy-GPP

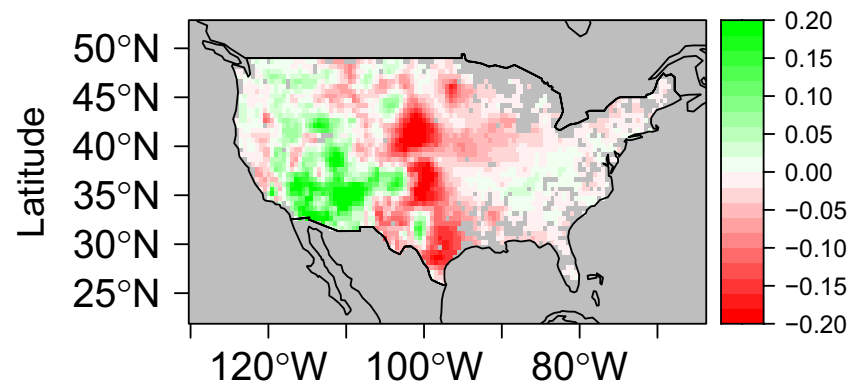

FLUXCOM-GPP

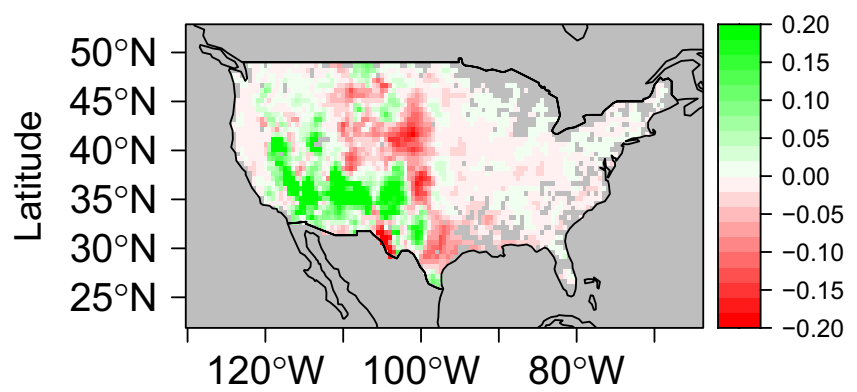

BESS-GPP

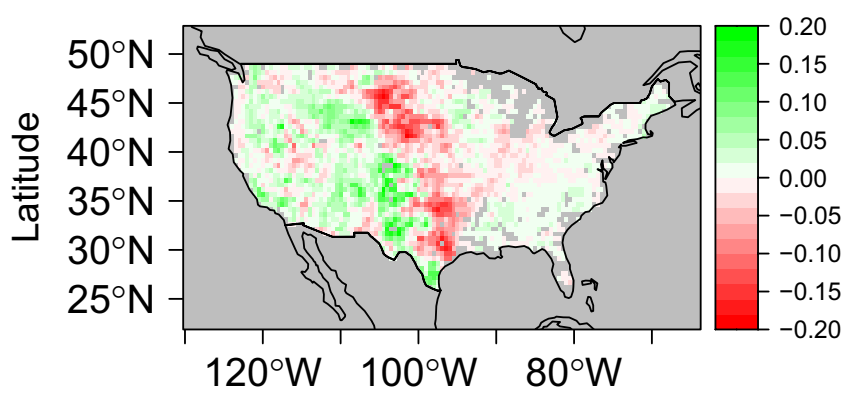

Trendy-NPP

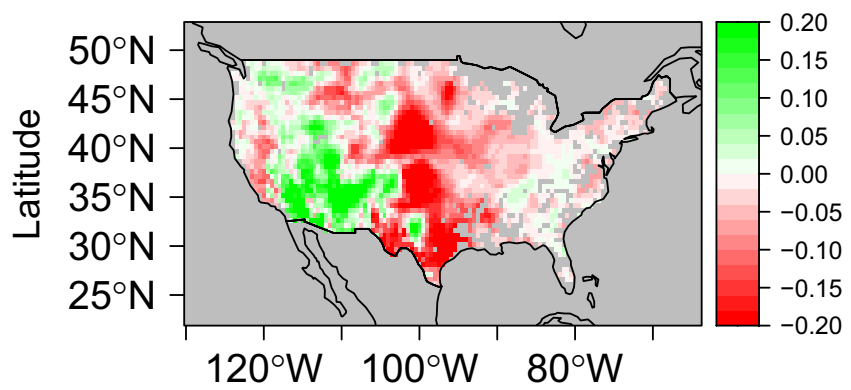

\section{Prentice-GPP}

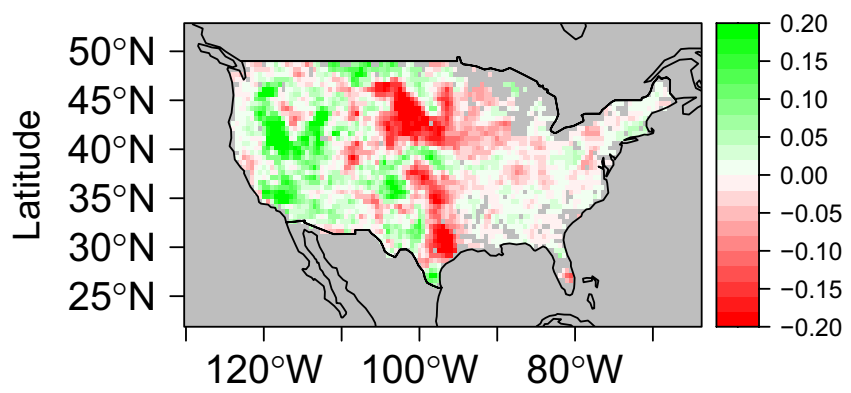

\section{Asymmetry of ecosystem productivity}

\author{
Pulse - Decline
}

FIGURE 1 Asymmetry responses (pulse - decline) of inter-annual ecosystem productivity at the biome scale computed from SMOS-IC L-band vegetation optical depth (SMOS-VOD), BESS-gross primary production (BESS-GPP), MODIS net primary productivity (MODIS-NPP), soil moisture corrected-Prentice model GPP (Prentice-GPP), machine learning approaches for upscaling biosphere-atmosphere fluxes from FLUXNET observations to global scale (FIUXCOM)-GPP and TRENDY models GPP and NPP within the 2010-2018 period (average of all the models)

forest and shrubs, respectively. The TRENDY models NPP shows similar results to SMOS-VOD (except over shrubs) and MODIS-NPP (except over evergreen forest). Asymmetry indices based on the GPP products were also similar across different products and mostly negative except over shrubs and evergreen forest. The main finding is that most datasets point to a large area of negative Al, with the exception of the dry southwest CONUS. These results thus indicate that the decline in terrestrial productivity during dry years was in general greater than the pulse of terrestrial productivity in wet years for most of the biomes during the last decade (i.e.; 2010-2018). The 


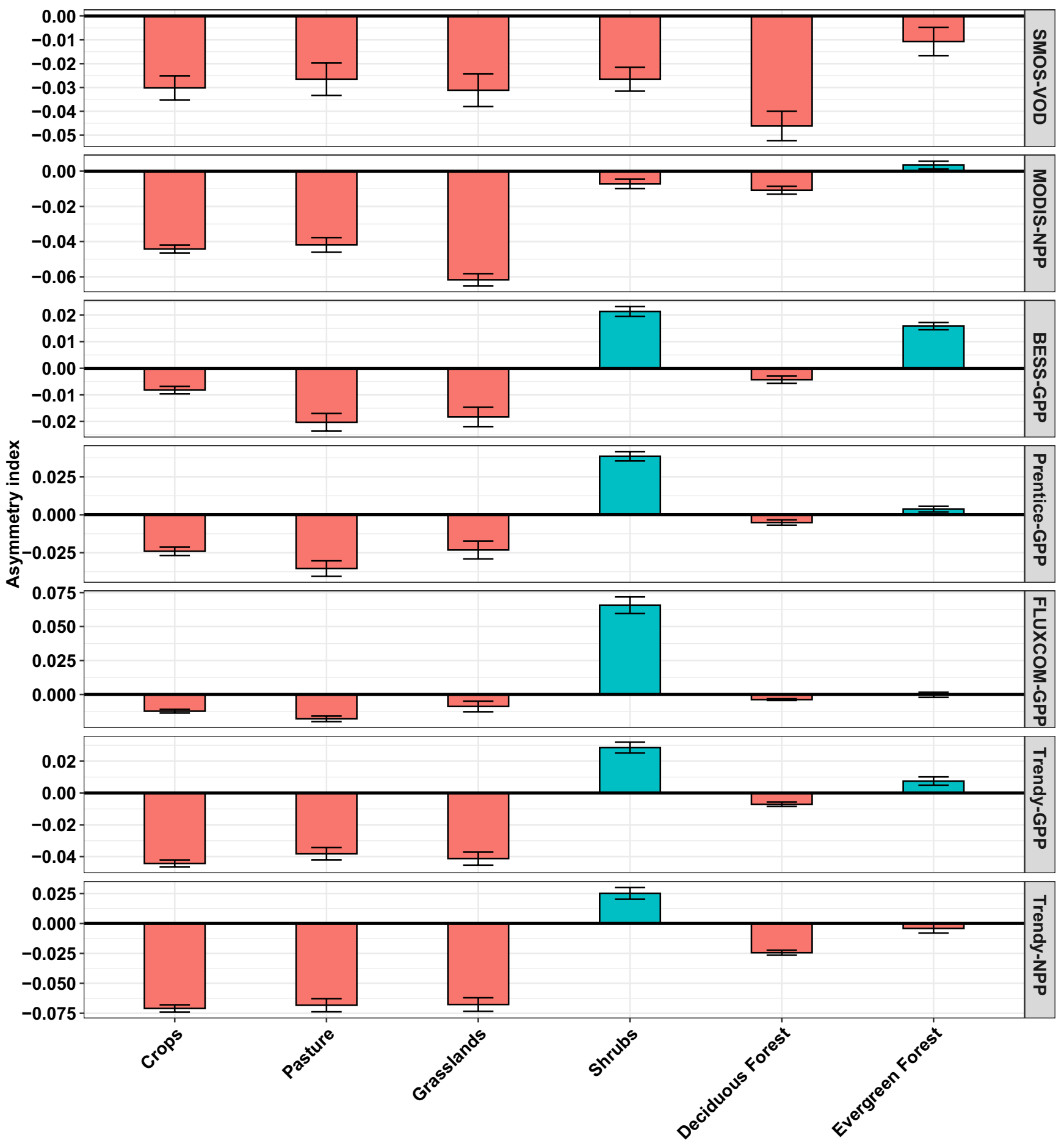

Biomes

FIGURE 2 Mean of asymmetry index (AI) responses of inter-annual ecosystem productivity at the biome scale estimated from SMOS-IC L-band vegetation optical depth (SMOS-VOD), BESS-Gross primary production (BESS-GPP), MODIS net primary productivity (MODISNPP), soil moisture corrected-P-model GPP (Prentice-GPP), machine learning approaches for upscaling biosphere-atmosphere fluxes from FLUXNET observations to global scale (Fluxcom)-GPP, and Trendy GPP and NPP within the 2010-2018 period. Error bars represent SEM

extent of this dominant negative asymmetry differs from the results obtained from the Long-Term Ecological Research sites studied by Knapp and Smith (2001) and that led them to conclude a dominant positive asymmetry across CONUS biomes.
The observed negative asymmetries of GPP and NPP shown in Figure 2 over grasslands and crops and the positive asymmetry over shrubs were also observed in the in situ flux tower data sets from Fluxnet2015 (Figure 3), irrespective of whether GPP was 


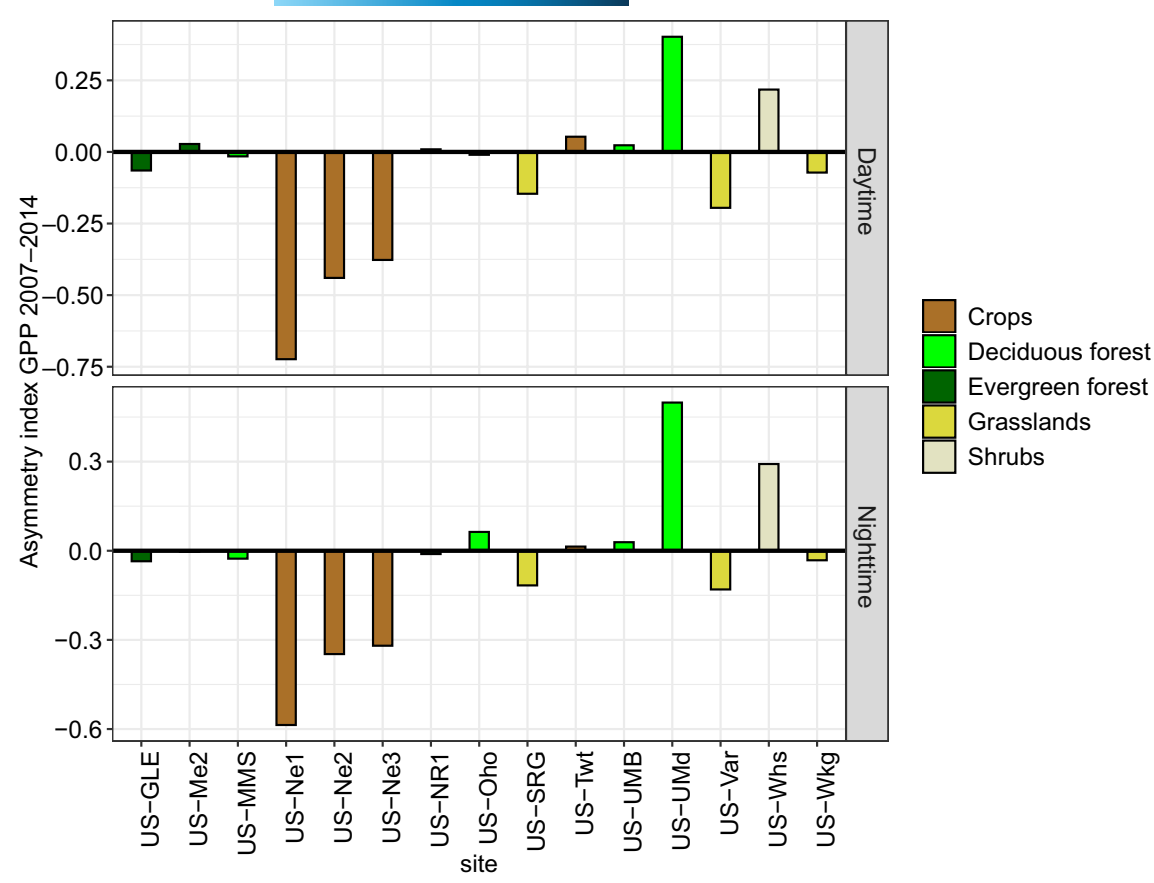

FIGURE 3 Asymmetry responses of inter-annual ecosystem productivity at the site scale from Fluxnet2015 during the 2007-2014 period. Gross Primary Production, from day-time and nighttime partitioning method, using Variable friction velocity (USTAR) Threshold (VUT) reference (GPP-REF) selected from GPP versions using model efficiency of USTAR thresholds from bootstrapping
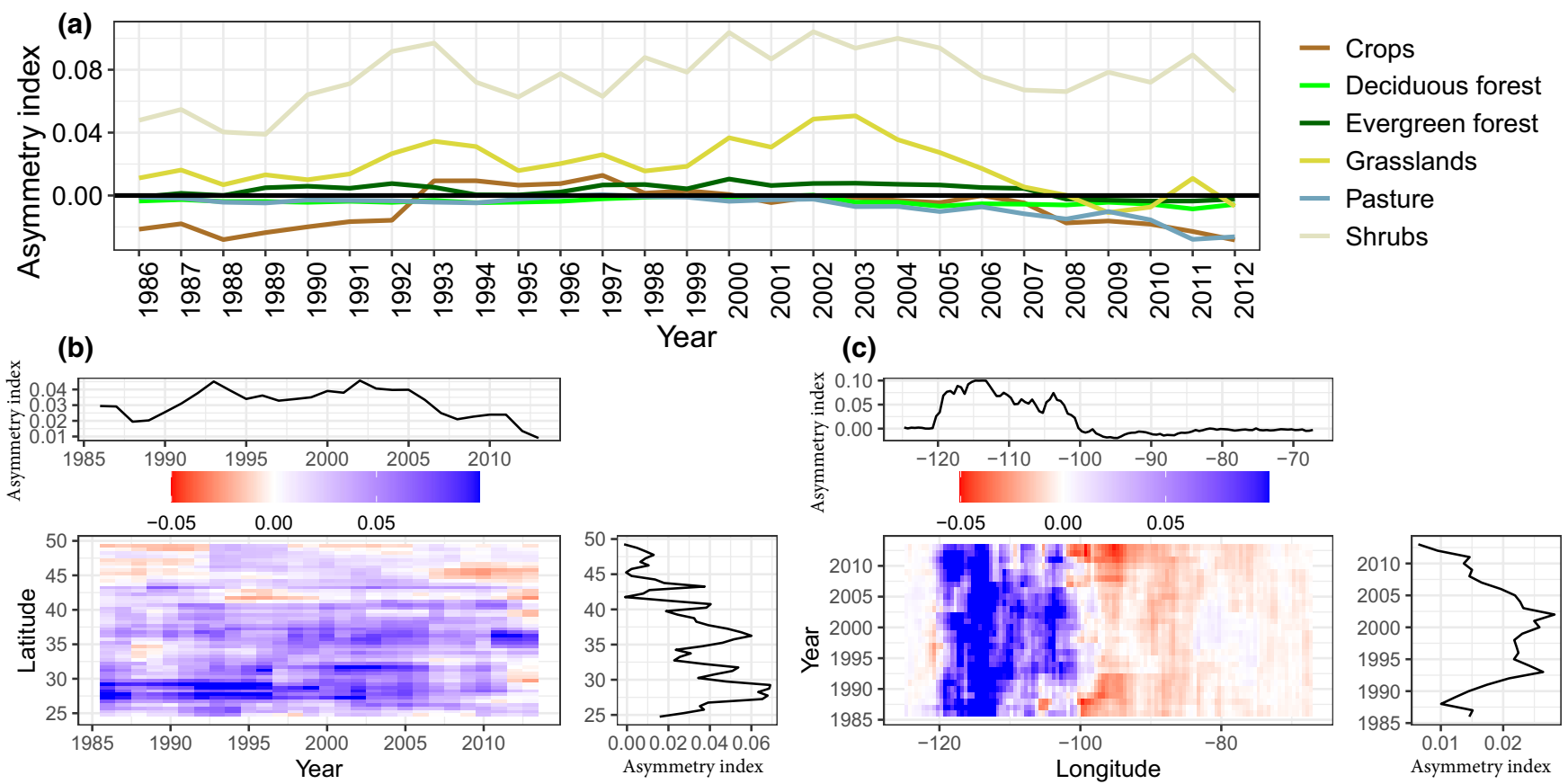

FIGURE 4 Decadal running mean asymmetry index (AI) of gross primary productivity (GPP) from machine learning approaches for upscaling biosphere-atmosphere fluxes from FLUXNET observations to global scale (FLUXCOM)-GPP as a function of biomes (a), latitude (b) and longitude (c). The Al is calculated from biome-mean GPP inter-annual variations using a running window of 10 years centered on each year of the $x$-axis. For instance, the value of the Al in the year 2000 was computed considering the period from 1995 to 2005

calculated from net ecosystem exchange using the night-time partitioning method (Reichstein et al., 2005) or the day-time partitioning method (Lasslop et al., 2010). Moreover, asymmetry responses of inter-annual ecosystem productivity at the site scale are not dependent on the GPP quantile (see Figure S4 for GPP versions with model efficiency [MEF] using the 25th, 50th, and 75th percentile of friction velocity [USTAR] thresholds from bootstrapping).

\section{3 | Decadal trends of asymmetry for each biome}

We then investigated the change in the asymmetry responses of ecosystem productivity from 1985 to 2016 (includes the period observed by Knapp \& Smith, 2001) with the period covered by the F-GPP (Figure 4) and soil moisture corrected-P-model GPP (Prentice-GPP) datasets (Figure S5) as a function of biomes, latitude 
and longitude. While the shrubs biome exhibited a persistent positive asymmetry during the entire period, the (natural) grasslands biome that represents $26 \%$ of CONUS appeared to have switched from positive to negative asymmetry over the last decade. This shift in the asymmetry of the GPP of natural grasslands was also found in the F-GPP products (both the day-time and night-time partitioning) over a longer period starting in the 1950s (Figure S6). For the grasslands biome, we calculated the Al for multiple lengths of the temporal windows $(9,11,13,15$ years, etc. up to the entire data set of 33 years; Figure S7). For all temporal windows, even the longest one (33 years), a decrease in the Al was observed, leading to negative Al during the last decade. The pasture biome exhibited a smaller asymmetry than (natural) grasslands, but this biome also became negative. Crops have a negative asymmetry during the last years (i.e., 2010-2016) but this biome did not show a clear long-term trend in Al.

\subsection{Spatial patterns of decadal trends of asymmetry}

The temporal trends of $\mathrm{Al}$ shown in Figure 4a varied with latitude (Figure $4 \mathrm{~b}$ ) and longitude (Figure $4 \mathrm{c}$ ). The Al values tended to decrease over time at all latitudes (except $\approx 35^{\circ}$ ) from the year 2012 onwards (although earlier at $\approx 45^{\circ}$ ). For longitude, two regions can be distinguished with $\mathrm{Al}$ remaining positive across all years in the West between $-120^{\circ}$ and $-100^{\circ} \mathrm{W}$ and $\mathrm{Al}$ becoming negative in the East between $-100^{\circ}$ and $-70^{\circ} \mathrm{W}$.

\subsection{Drivers of asymmetry}

At the CONUS scale, amongst the five variables (see Section 2.2) used to predict the annual asymmetry of ecosystem productivity with the RF models, AiPR was the most important predictor variable (Figure 5) followed by RATio (annual precipitation/PET ratio). At the biome scale, CVPR (precipitation variability) and MeanPR (mean annual precipitation) were the most important indicators over pasture and grasslands, respectively. RATio was the most important predictor variable over forests and crops. MaxNPP ranked third for grasslands and fourth for the other biomes except crops where it was the least important variable.

At the CONUS scale, precipitation asymmetry was the most important variable and, therefore, evaluated here as a key potential driver of the asymmetry patterns of productivity. Annual precipitation does present consistent negative asymmetry over grasslands, evergreen forest and crops during the last decade for both GRIDMET (Figure 6a), and CPC precipitation products (Figure S8; only for grasslands). We also calculated the Al for multiple lengths of the temporal windows (9 years, 11, 13, 15, etc., up to the entire data set) to explore the maximum cases of asymmetry possible over grasslands (including the Climate Hazards Group InfraRed Precipitation with Station data (CHIRPS) and Global Precipitation Climatology Centre (GPCC) precipitation datasets described in the Supporting Information). We found that the three CPC, GPCC and CHIRPS precipitation datasets are consistent: the longest the period, the highest the positive Al in productivity (Figure S9). These trends in precipitation also translated well into GPP trends (Figure S7). Conversely, the
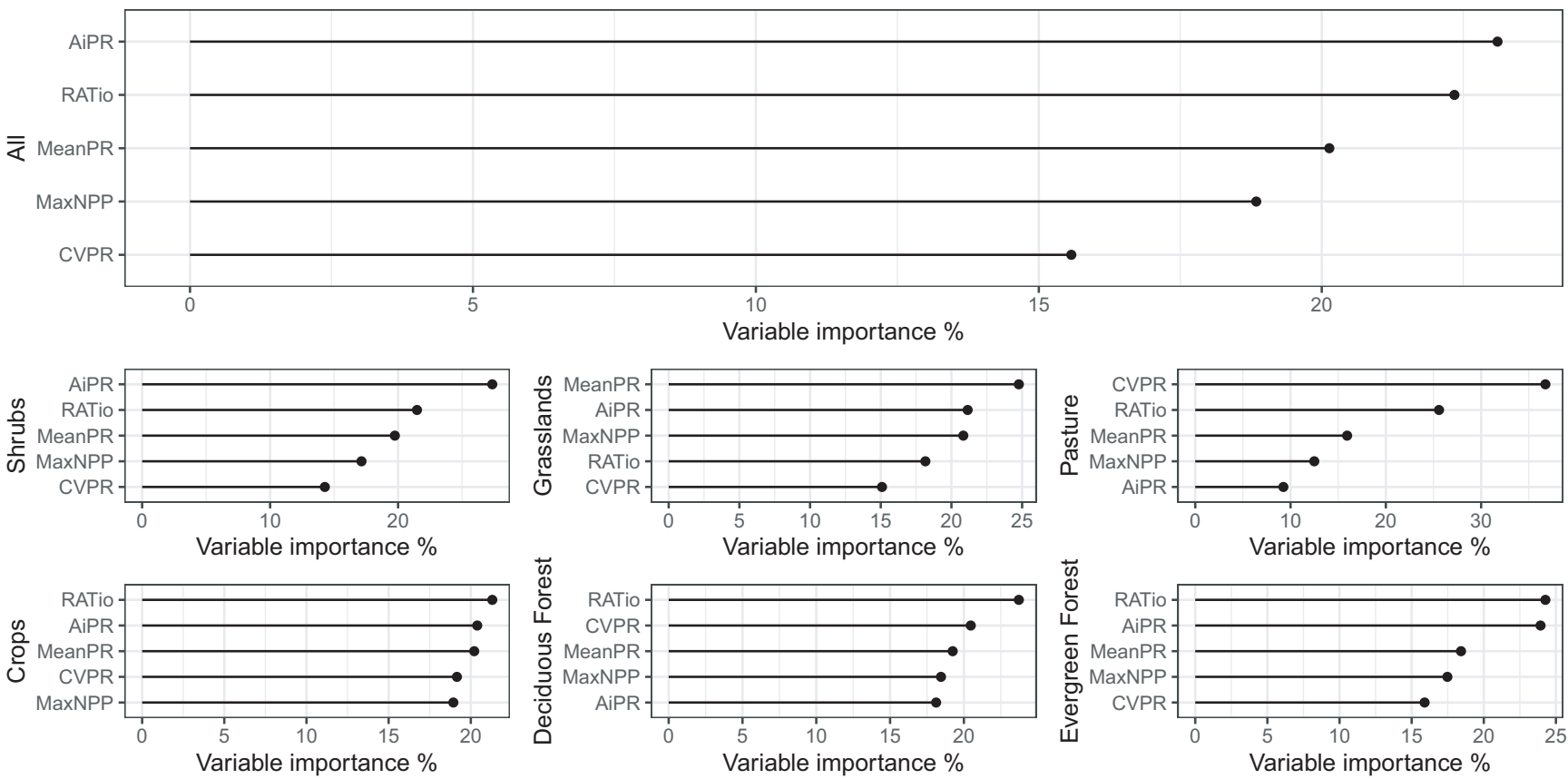

FIGURE 5 Variable importance of the five predictors used to predict asymmetry index of ecosystem productivity using all pixels of the created maps (i.e., across the whole CONUS) and per biome. High values of percent indicate more important variables in the Random Forests models. The five predictor variables were asymmetry of rainfall anomalies (AiPR), ecosystem productivity potential (MaxNPP), precipitation variability (CVPR), annual precipitation/potential evapotranspiration ratio (RATio), and mean annual precipitation (MeanPR) 

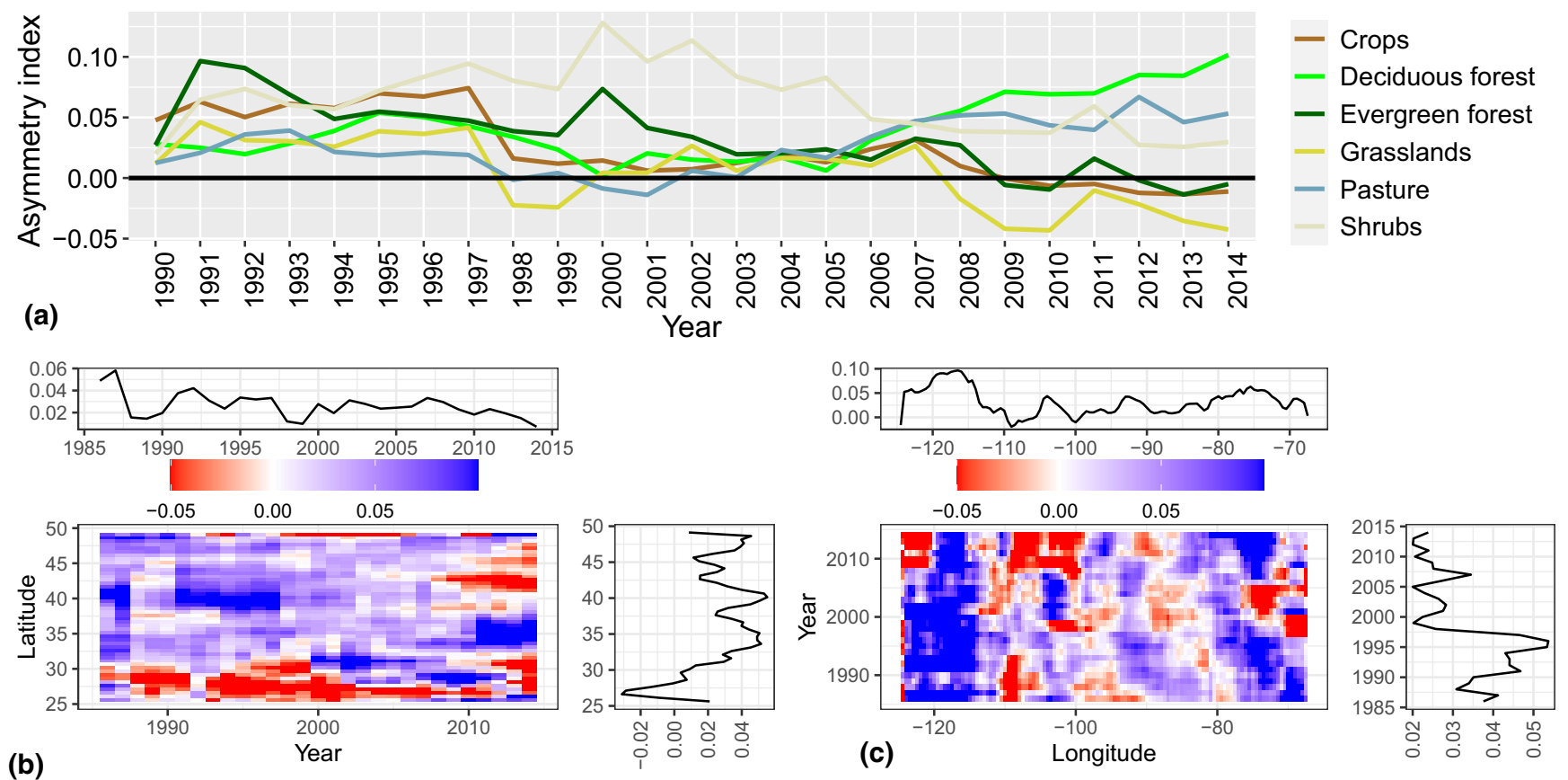

FIGURE 6 Changes in the asymmetry index (AI) of precipitation from Gridded surface meteorological dataset (GRIDMET) over 19902014 as a function of biomes (a), latitude (b) and longitude (c). The Al was calculated from biome-mean precipitation inter-annual variations using a running window of 10 years centered on each year of the $x$-axis. For instance, the value of the Al in the year 2000 was computed over the period from 1995 to 2005

Al of precipitation is positive for shrubs and does not present clear trends for either GRIDMET or CPC products.

Similar to the temporal trends of the Al of ecosystem productivity, the temporal trends for precipitation, in Figure 6a, vary with latitude (Figure $6 \mathrm{~b}$ ) and longitude (Figure $6 \mathrm{c}$ ). The Al values decrease for all latitudes (except for latitude $\approx 35^{\circ}$ ) starting from the year 2010 . In addition, a band of negative asymmetry between the latitudes $20^{\circ}$ and $30^{\circ}$ throughout the whole period was observed. For longitude, there is a general decrease in the Al of precipitation over the 20002014 period.

To further relate the vegetation proxies to precipitation anomalies directly, the average pulses and declines were grouped by biomes for both productivity and precipitation (Figures S10 and S11). The magnitude of the relative productivity pulses or declines were positively correlated to precipitation pulses and declines. Biomes clearly differed in their sensitivity to drought and wetter years, with grasslands being the most responsive (Vicente-Serrano et al., 2013). Confirming the findings of Knapp and Smith (2001), grasslands and shrubs demonstrated more plasticity than the other biomes to adapt production in response to experiencing high precipitation anomalies.

\section{4 | DISCUSSION}

Similar spatial patterns in the asymmetry response (Al) were found among the different GPP productivity metrics but varied considerably with the MODIS-NPP and SMOS-VOD proxies. SMOS-VOD, which is a proxy of AGB, corresponding roughly to ANPP for annual vegetation, indicated a more widespread negative asymmetry. This may reflect the fact that drought decreases the amount of carbon and water allocated to AGB in dry years, thus reducing the SMOSVOD signal and eventually negating the positive GPP asymmetry (e.g., shorter turnover time of aboveground plant tissues). Moreover, for grasslands, shrubs and forests, covariance between mortality and ANPP may lead to a more negative AI of AGB values compared to the Al of GPP. The wider spread of negative asymmetry found with SMOS-VOD compared to the GPP products may reflect an increase in plant mortality in dry years, causing more relative AGB declines than GPP declines during dry years. SMOS-VOD is probably a much more sensitive metric to water stress than vegetation indices in forests of western US where "evergreen" trees still appear green even though they may be transpiring very little water.

The aggregated productivity trends of each biome (Figure 4) in the last decade were in relatively good agreement with the aggregated trends of precipitation (Figure 6). This can be related to the fact that inter-annual anomalies of precipitation have a strong impact on variations of soil moisture (Humphrey et al., 2017), plant productivity (Ahlström et al., 2015; Stocker et al., 2019) with lagged effects on vegetation (Papagiannopoulou et al., 2017), and mortality (Wang et al., 2018). The impact of rainfall on the Al of productivity was even more evident when results were binned by mean annual precipitation (Figure 7). In general, a decrease of the Al with spatially increasing rainfall was evident for all products (Figure 7a). The relative magnitude of the negative and positive pulses decreases with increasing mean annual precipitation and 

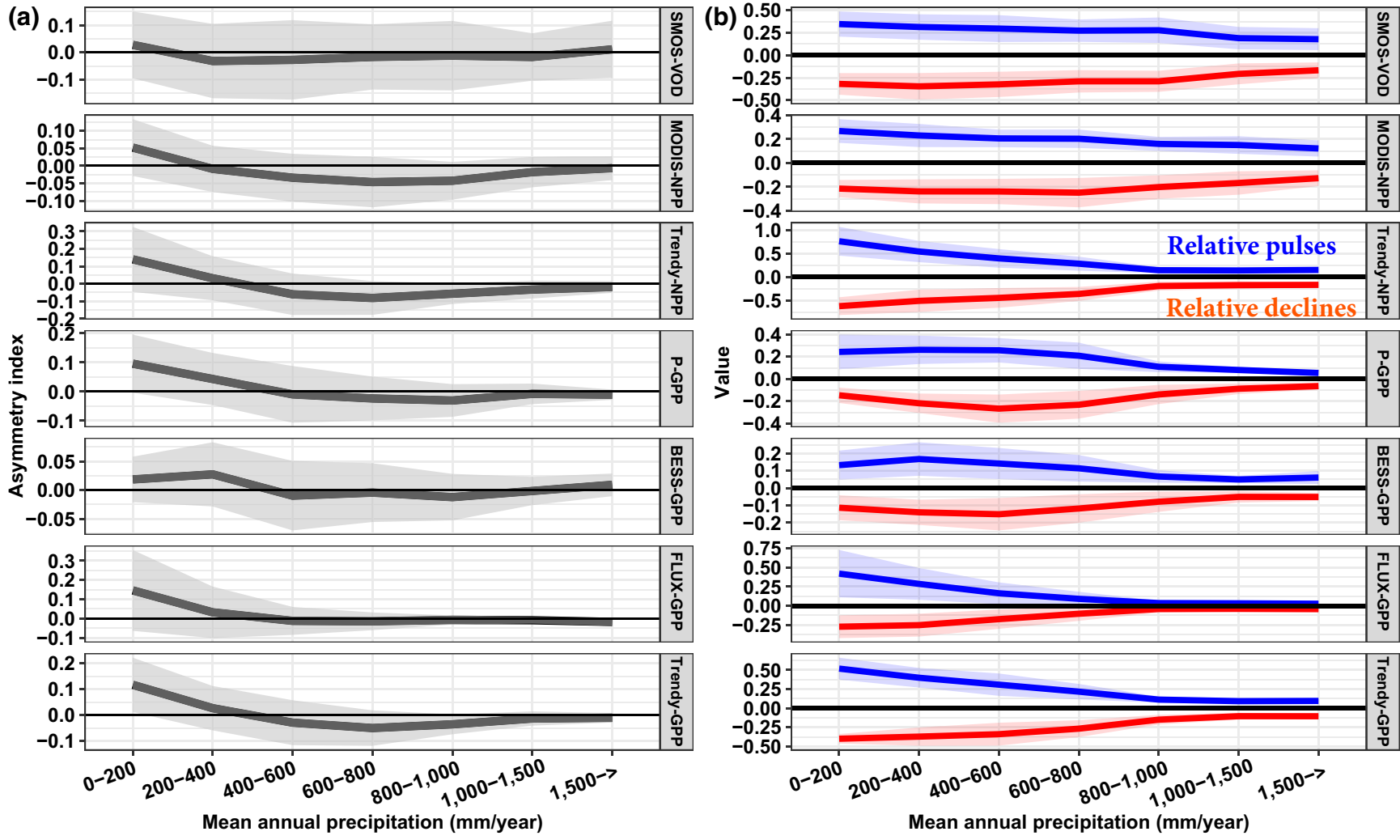

FIGURE 7 (a) Median and range of the asymmetry index ( $\mathrm{Al}$ ) as a function of increasing mean annual precipitation across the CONterminous United States (CONUS) for a proxy of biomass (SMOS_IC L-VOD) and different proxies of primary productivity and (b) magnitudes of relative pulses and relative declines of biomass and productivity for increasing mean annual precipitation across the CONUS. The $\mathrm{Al}$ is the difference between relative pulse and decline, which was grouped into mean annual rainfall bins. The shaded areas represent the standard deviation of the $\mathrm{Al}$

both pulses decrease to 0 for very wet regions (Figure $7 b)$. The $\mathrm{Al}$ is found to be a function of mean rainfall: more positive asymmetry is found in dry areas and more negative asymmetry in wet areas, but neutral $\mathrm{Al}$ (values close to 0 ) are found in very wet conditions. Therefore, functional asymmetry is greatest in dry areas and least in wet regions. Considering negative pulses, declines in GPP become smaller in dry regions in five of the seven products. The Al becomes negative for most of the GPP and NPP products with mean precipitation in the range $200-400 \mathrm{~mm} /$ year. This threshold of precipitation is in relative agreement with previous results (Gherardi \& Sala, 2019). This may be because ecosystems in these dry areas reached such low levels of GPP that there is not much capacity for further reductions. In wet regions, negative precipitation pulses (declines) are generally weak. The worst case of negative asymmetry appears to be in intermediate conditions where vegetation is not adapted to very dry conditions and to strong negative precipitation anomalies that may happen abruptly. Note that the Al values become negative earlier for SMOS-VOD suggesting that it may be a more sensitive indicator of drought stress.

We also examined historical inter-annual spatio-temporal variations (1990-2018) of different drought indices to better understand why there is a temporal trend from positive asymmetry towards neutral or negative asymmetry over the last decade. The period from 2010 to 2018 was warmer than the previous decade from 2000 to 2009 and the decade from 1990 to 1999 over the CONUS (Figure S12). The PDSI was negative during 2000-2018 indicating greater drought than during 1990-1999. Similarly, there was an overall low VHI (Kogan, 2001) indicating that plants were under more stress during the decade of 2010-2018 than during the previous decades. The severe droughts in 2012, 2016 and 2017 are suspected to have had a major impact on the asymmetry patterns of Grasslands that became negative (Figure S13) while VHI and PDSI were lowest and temperature was higher than the long-term average (1981-2018). The period before the year 2000 seems to be wetter than the two recent decades, thus providing better environmental conditions for ecosystem productivity and perhaps also contributing to the positive asymmetry found by previous studies (Knapp \& Smith, 2001). For the recent decade, despite the variety in the different ecological characteristics of the biomes over the CONUS, productivity for non-forest biomes over the CONUS was more impacted during drought years than during wet years, namely productivity pulse gains during extreme wet years were lower than drought-induced productivity reductions. Impacts of droughts, mainly the 2012 drought, on terrestrial carbon fluxes (i.e., GPP) have been investigated by Wolf et al. (2016) who have found too that the decrease in GPP during summer was much larger than the increase of spring GPP for 2012 and greater respiration losses in summer and 
fall, resulting in a moderate loss of annual GPP $(-0.38 \mathrm{pg} \mathrm{C})$ over the CONUS in 2012.

Persistent positive asymmetries of ecosystem productivity were observed over shrubs (Figures 2 and 3 ) for all proxies except SMOSVOD and MODIS-NPP. The shrubs biome positive Al values were associated with positive asymmetries in precipitation (Figure 6a). Winkler et al. (2019) have evaluated meteorological drought-induced events and the influence of abiotic and biotic site factors in driving mortality responses of some plant species in the Colorado Plateau Desert. Shrubs species were generally found to be resistant to meteorological drought (attributed to their ability to access deeper soil water). The positive asymmetry responses for shrubs and other biomes may be linked with a relatively strong resilience to drought stress that is possibly related to their ability to grow and maintain extensive lateral and/or deep roots, as illustrated in Figures S14 and S15 where pulses and declines generally increase for increasing maximum rooting depths (Fan et al., 2017).

The negative asymmetry patterns of productivity (GPP and NPP) for non-shrub short-stature vegetation: grasslands and crops (Figure 3 ) in the last decade were in good agreement with the negative asymmetry of precipitation (Figure 6a). The trends in precipitation over grasslands (Figure S9) corresponded well to GPP trends (Figure S7) over a longer period indicating that grasslands respond instantly to drought with negative asymmetry. This means that the sign and magnitude of precipitation changes have large effects on the grasslands ecosystem productivity (Gherardi \& Sala, 2015; Sala et al., 2012). This is expected as grasslands with small pools of carbon (lower biomass) and shallow rooting depths, often exhibit great declines in greenness with water stress (Sims et al., 2014).

Besides AiPR, RATio was the second most important predictor variable at the CONUS scale and the most important predictor variable over forests and crops (Figure 5). This means that the productivity asymmetry over forests and crops can be explained by both precipitation and evapotranspiration. Forests have often sufficient water surplus to meet the evapotranspiration demand even during dry years (Knapp \& Smith, 2001) while a water deficit in crops can be mediated by irrigation reducing the dependence of crops on rainfall (Leng et al., 2016).

Other studies have shown that the sensitivity of the NDVI to drought was also greatest across the Great Plains (Sims et al., 2014) and that changes in grasslands NDVI were also more sensitive to drought in that region where grasslands appear to be more anisohydric (Konings et al., 2017). This is consistent too with a recent study of model results by $\mathrm{Wu}$ et al. (2018) who found a negative asymmetry for the mean resulting from an ensemble of models (15 ecosystem models) predicting ANPP productivity under normal inter-annual precipitation variability across three grasslands sites over the CONUS. Such a prevalent negative asymmetry for intermediate ecozones between mesic and semiarid is, however, not in line with previous investigations that used data collected about thirty years ago at the ecosystem scale (Knapp \& Smith, 2001). The latter study found that NPP productivity in the mesic ecozone of Kansas responded more strongly in wet versus dry years, having positive asymmetry due to drought tolerance/resistance mechanisms at the ecosystem scale. The inclusion of much more extreme dry years in our analysis than observed by Knapp and Smith (2001) may explain this discrepancy. Responses to climate extremes are expected to vary significantly from nominal wet and dry years (Knapp et al., 2017; Smith, 2011). This temporal analysis also suggests that the Al of grasslands has shifted over time.

In addition, recent studies have reported significant impacts of other climatic factors on different crops over the CONUS such as thermal time (growing degree-days or GDD), first and last annual frost, climatological growing season (CGS) and growing season length. For instance, Kukal and Irmak (2018), have suggested that long-term thermal trends have also impacted the US crop systems with a positive response to CGS and a negative response to increase in GDD. Furthermore, long-term land use changes ( $8 \%$ of the landscape experienced a land cover change between 2001 and 2016) in the CONUS alter biophysical surface characteristics and can therefore lead to changes of ecosystem productivity (Homer et al., 2020).

\section{CONCLUSION}

Overall, a negative asymmetry resulting from a greater decline of biomass in dry years than a positive pulse of biomass in wet years was observed over the CONUS from 2010 to 2018, particularly for grasslands. This negative signature was revealed for both ecosystem productivity and precipitation, the former being possibly a consequence of the latter. The shift in asymmetries from positive to negative was observed for most biomes possibly caused by warm and dry climate conditions prevailing over 2010-2018 and notably the severity of the recent droughts in 2012. For GPP, evergreen forest and shrubs ecosystems generally showed positive asymmetry, consistent with previous studies by Knapp and Smith (2001), whereas drought led to negative asymmetries for the other ecosystems. Importantly, this result was robust across the different types of GPP products used in this analysis as well as across biomass and NPP, suggesting that as drought severity increases, shifts in asymmetric responses to rainfall anomalies are occurring. This evaluation of $\mathrm{Al}$ should be extended to other regions by examining directly rain use efficiency changes as a function of mean annual rainfall with attention to specific effects of fire, high temperatures, mortality, and their impacts on AGB.

\section{ACKNOWLEDGEMENTS}

The authors would like to thank the TOSCA (Terre Océan Surfaces Continentales et Atmosphère) CNES (Centre national d'études spatiales, France) program for funding this research work. We are grateful for the invaluable databases. We thank Pr. Youngryel Ryu and Dr. Martin Jung for the BESS-model and FIUXCOM outputs, respectively and three anonymous reviewers for comments.

\section{DATA AVAILABILITY STATEMENT}

The datasets that support the findings of this study are publicly available: the SMOS-IC L-VOD (https://ib.remote-sensing.inrae. 
$\mathrm{fr} /$ ); the MODIS algorithm (MOD17) NPP (http://files.ntsg.umt. edu/data/NTSG_Products/MOD17/MODIS_250/modis-250$\mathrm{npp} /$ ); the GPP product from the Prentice model (https://zenodo. org/record/1423484); the FLUXCOM-GPP product (https://www. bgc-jena.mpg.de/geodb/projects/Home.php); the Breathing Earth System Simulator GPP product (http://environment.snu.ac.kr/ bess/); the latest available version (Trendy-v7) of the ensemble of eight Trendy ecosystem models and land surface models (trendyv7@trendy.ex.ac.uk); the in situ FLUXNET2015 GPP (http:// fluxnet.fluxdata.org/data/fluxnet2015-dataset/); the Climate Prediction Centre Global Unified Gauge-Based Analysis of Daily Precipitation (https://www.esrl.noaa.gov/psd/data/gridded/data. cpc.globalprecip.html); the GRIDMET surface meteorological data of daily maximum temperature, minimum temperature, precipitation accumulation and 10-day Palmer Drought Severity Index (http://www.climatologylab.org/gridmet.html); the CRU TS Version 4 (Climatic Research Unit gridded Time Series) monthly precipitation and potential evapotranspiration dataset (http://www. cru.uea.ac.uk/data); the USGS National Land Cover Dataset 2011 (https://catalog.data.gov/dataset/nlcd-2011-land-cover-2011edition-amended-2014-national-geospatial-data-asset-ngda-landuse-la); the vegetation health Index (https://www.star.nesdis. noaa.gov/smcd/emb/vci/VH/vh_ftp.php); and the maximum rooting depth (https://wci.earth2observe.eu/thredds/catalog/usc/rootdepth/catalog.html).

\section{ORCID}

Amen Al-Yaari (iD https://orcid.org/0000-0001-7530-6088 Jean-Pierre Wigneron (iD https://orcid.org/0000-0001-5345-3618 Jerome Ogée (iD https://orcid.org/0000-0002-3365-8584

\section{REFERENCES}

Abatzoglou, J. T. (2013). Development of gridded surface meteorological data for ecological applications and modelling. International Journal of Climatology, 33, 121-131. https://doi.org/10.1002/joc.3413

Ahlström, A., Raupach, M. R., Schurgers, G., Smith, B., Arneth, A., Jung, M., ... Zeng, N. (2015). The dominant role of semi-arid ecosystems in the trend and variability of the land $\mathrm{CO}_{2}$ sink. Science, 348(6237), 895-899. https://doi.org/10.1126/science.aaa1668

Al-Yaari, A., Wigneron, J. P., Dorigo, W., Colliander, A., Pellarin, T., Hahn, S., ... De Lannoy, G. (2019). Assessment and inter-comparison of recently developed/reprocessed microwave satellite soil moisture products using ISMN ground-based measurements. Remote Sensing of Environment, 224, 289-303. https://doi.org/10.1016/j. rse.2019.02.008

Asner, G. P., Brodrick, P. G., Philipson, C., Vaughn, N. R., Martin, R. E., Knapp, D. E., ... Coomes, D. A. (2018). Mapped aboveground carbon stocks to advance forest conservation and recovery in Malaysian Borneo. Biological Conservation, 217, 289-310. https://doi. org/10.1016/j.biocon.2017.10.020

Bai, Y., Wu, J., Xing, Q., Pan, Q., Huang, J., Yang, D., \& Han, X. (2008). Primary production and rain use efficiency across a precipitation gradient on the Mongolia plateau. Ecology, 89(8), 2140-2153. https:// doi.org/10.1890/07-0992.1

Baldocchi, D., Falge, E., Gu, L., Olson, R., Hollinger, D., Running, S., ... Wofsy, S. (2001). FLUXNET: A new tool to study the temporal and spatial variability of ecosystem-scale carbon dioxide, water vapor, and energy flux densities. Bulletin of the American Meteorological Society, 82, 2415-2434. https://doi.org/10.1175/1520-0477(2001)082<2415:fantts $>2.3 . c 0 ; 2$

Bento, V. A., Gouveia, C. M., DaCamara, C. C., \& Trigo, I. F. (2018). A climatological assessment of drought impact on vegetation health index. Agricultural and Forest Meteorology, 259, 286-295. https://doi. org/10.1016/j.agrformet.2018.05.014

Bousquet, P., Peylin, P., Ciais, P., Le Quere, C., Friedlingstein, P., \& Tans, P. P. (2000). Regional changes in carbon dioxide fluxes of land and oceans since 1980. Science, 290(5495), 1342-1346. https://doi. org/10.1126/science.290.5495.1342

Brandt, M., Yue, Y., Wigneron, J. P., Tong, X., Tian, F., Jepsen, M. R., ... Fensholt, R. (2018). Satellite-observed major greening and biomass increase in South China Karst during recent decade. Earth's Future, 6, 1017-1028. https://doi.org/10.1029/2018EF000890

Breiman, L. (2001). 2001 4_Method_Random_Forest. Machine Learning. https://doi.org/10.1017/CBO9781107415324.004

Chen, M., Shi, W., Xie, P., Silva, V. B. S., Kousky, V. E., Wayne Higgins, R., \& Janowiak, J. E. (2008). Assessing objective techniques for gaugebased analyses of global daily precipitation. Journal of Geophysical Research: Atmospheres, 113. https://doi.org/10.1029/2007jd009132

Fahey, T. J., \& Knapp, A. K. (2007). Principles and standards for measuring net primary production. New York, NY: Oxford University Press.

Fan, L., Wigneron, J. P., Ciais, P., Chave, J., Brandt, M., Fensholt, R., ... Peñuelas, J. (2019). Satellite-observed pantropical carbon dynamics. Nature Plants, 5, 944-951. https://doi.org/10.1038/s4147 7-019-0478-9

Fan, Y., Miguez-Macho, G., Jobbágy, E. G., Jackson, R. B., \& Otero-Casal, C. (2017). Hydrologic regulation of plant rooting depth. Proceedings of the National Academy of Sciences of the United States of America, 114, 10572-10577. https://doi.org/10.1073/pnas.1712381114

Fernandez-Moran, R., Al-Yaari, A., Mialon, A., Mahmoodi, A., Al Bitar, A., De Lannoy, G., ... Wigneron, J. P. (2017). SMOS-IC: An alternative SMOS soil moisture and vegetation optical depth product. Remote Sensing, 9, 457. https://doi.org/10.3390/rs9050457

Gherardi, L. A., \& Sala, O. E. (2015). Enhanced precipitation variability decreases grass- and increases shrub-productivity. Proceedings of the National Academy of Sciences of the United States of America, 112, 12735-12740. https://doi.org/10.1073/pnas.1506433112

Gherardi, L. A., \& Sala, O. E. (2019). Effect of interannual precipitation variability on dryland productivity: A global synthesis. Global Change Biology, 25(1), 269-276. https://doi.org/10.1111/gcb.14480

Harris, I., Osborn, T. J., Jones, P., \& Lister, D. (2020). Version 4 of the CRU TS monthly high-resolution gridded multivariate climate dataset. Scientific Data, 7(1). https://doi.org/10.1038/s41597-020-0453-3

Hoerling, M., Eischeid, J., Kumar, A., Leung, R., Mariotti, A., Mo, K., ... Seager, R. (2013). Causes and predictability of the 2012 Great Plains Drought. Bulletin of the American Meteorological Society, 95, 269-282. https://doi.org/10.1175/bams-d-13-00055.1

Holdridge, L. R. (1947). Determination of world plant formations from simple climatic data. Science, 105(2727), 367-368. https://doi. org/10.1126/science.105.2727.367

Homer, C., Dewitz, J., Jin, S., Xian, G., Costello, C., Danielson, P., ... Riitters, K. (2020). Conterminous United States land cover change patterns 2001-2016 from the 2016 National Land Cover Database. ISPRS Journal of Photogrammetry and Remote Sensing, 162, 184-199. https://doi.org/10.1016/j.isprsjprs.2020.02.019

Hsu, J. S., Powell, J., \& Adler, P. B. (2012). Sensitivity of mean annual primary production to precipitation. Global Change Biology, 18, 22462255. https://doi.org/10.1111/j.1365-2486.2012.02687.x

Humphrey, V., Gudmundsson, L., \& Seneviratne, S. I. (2017). A global reconstruction of climate-driven subdecadal water storage variability. Geophysical Research Letters, 44, 2300-2309. https://doi. org/10.1002/2017gl072564 
Huxman, T. E., Smith, M. D., Fay, P. A., Knapp, A. K., Shaw, M. R., Lolk, M. E., ... Williams, D. G. (2004). Convergence across biomes to a common rain-use efficiency. Nature, https://doi.org/10.1038/natur e02561

Huxman, T. E., Snyder, K. A., Tissue, D., Leffler, A. J., Ogle, K., Pockman, W. T., ... Schwinning, S. (2004). Precipitation pulses and carbon fluxes in semiarid and arid ecosystems. Oecologia, 141(2), 254-268. https:// doi.org/10.1007/s00442-004-1682-4

Jiang, C., \& Ryu, Y. (2016). Multi-scale evaluation of global gross primary productivity and evapotranspiration products derived from Breathing Earth System Simulator (BESS). Remote Sensing of Environment, 186, 528-547. https://doi.org/10.1016/j.rse.2016.08.030

Joanes, D. N., \& Gill, C. A. (1998). Comparing measures of sample skewness and kurtosis. Journal of the Royal Statistical Society: Series D (The Statistician), 47(1), 183-189. https://doi. org/10.1111/1467-9884.00122

Jung, M., Koirala, S., Weber, U., Ichii, K., Gans, F., Camps-Valls, G., ... Reichstein, M. (2019). The FLUXCOM ensemble of global land-atmosphere energy fluxes. Scientific Data, 6, 74. https://doi.org/10.1038/ s41597-019-0076-8

Jung, M., Reichstein, M., Schwalm, C. R., Huntingford, C., Sitch, S., Ahlström, A., ... Zeng, N. (2017). Compensatory water effects link yearly global land $\mathrm{CO}_{2}$ sink changes to temperature. Nature, 541, 516 . https://doi.org/10.1038/nature20780

Jung, M., Schwalm, C., Migliavacca, M., Walther, S., Camps-Valls, G., Koirala, S., ... Reichstein, M. (2020). Scaling carbon fluxes from eddy covariance sites to globe: Synthesis and evaluation of the FLUXCOM approach. Biogeosciences, 17(5), 1343-1365. https://doi. org/10.5194/bg-17-1343-2020

Kerr, Y. H., Al-Yaari, A., Rodriguez-Fernandez, N., Parrens, M., Molero, B., Leroux, D., ... Wigneron, J. P. (2016). Overview of SMOS performance in terms of global soil moisture monitoring after six years in operation. Remote Sensing of Environment, 180, 40-63. https://doi. org/10.1016/j.rse.2016.02.04

Knapp, A. K., Ciais, P., \& Smith, M. D. (2017). Reconciling inconsistencies in precipitation-productivity relationships: Implications for climate change. New Phytologist, 214, 41-47. https://doi.org/10.1111/ nph.14381

Knapp, A. K., \& Smith, M. D. (2001). Variation among biomes in temporal dynamics of aboveground primary production. Science, 291(5503), 481-484. https://doi.org/10.1126/science.291.5503.481

Kogan, F. N. (2001). Operational space technology for global vegetation assessment. Bulletin of the American Meteorological Society, 82, 19491964. https://doi.org/10.1175/1520-0477(2001)082<1949:ostfg v>2.3.co;2

Konings, A. G., Williams, A. P., \& Gentine, P. (2017). Sensitivity of grassland productivity to aridity controlled by stomatal and xylem regulation. Nature Geoscience, 10, 284-288. https://doi.org/10.1038/ ngeo2903

Kukal, M. S., \& Irmak, S. (2018). U.S. agro-climate in 20th century: Growing degree days, first and last frost, growing season length, and impacts on crop yields. Scientific Reports, 8(1). https://doi.org/10.1038/s4159 8-018-25212-2

Lasslop, G., Reichstein, M., Papale, D., Richardson, A. D., Arneth, A., Barr, A., ... Wohlfahrt, G. (2010). Separation of net ecosystem exchange into assimilation and respiration using a light response curve approach: Critical issues and global evaluation. Global Change Bioloy, 16, 187-208. https://doi.org/10.1111/j.1365-2486.2009.02041.x

Le Quéré, C., Andrew, R. M., Friedlingstein, P., Sitch, S., Hauck, J., Pongratz, J., ... Zheng, B. (2018). Global carbon budget 2018. Earth System Science Data, 10, 2141-2194. https://doi.org/10.5194/ essd-10-2141-2018

Leng, G., Zhang, X., Huang, M., Asrar, G. R., \& Leung, L. R. (2016). The role of climate covariability on crop yields in the Conterminous United States. Scientific Reports, 6(1). https://doi.org/10.1038/srep33160
Li, X., Al-Yaari, A., Schwank, M., Fan, L., Frappart, F., Swenson, J., \& Wigneron, J. P. (2020). Compared performances of SMOS-IC soil moisture and vegetation optical depth retrievals based on Tau-Omega and TwoStream microwave emission models. Remote Sensing of Environment, 236, 111502. https://doi.org/10.1016/j.rse.2019.111502

Liaw, A., \& Wiener, M. (2002). Classification and regression with random forest. R News, 2, 18-22.

Liu, Z., Ballantyne, A. P., \& Cooper, L. A. (2019). Biophysical feedback of global forest fires on surface temperature. Nature Communications, 10, 214. https://doi.org/10.1038/s41467-018-08237-z

Melillo, J. M., Richmond, T. (T. C.), \& Yohe, G. W. (2014). Climate change impacts in the United States: The third national climate assessment. Washington, DC: U.S. Government Printing Office, 841 pp. https:// doi.org/10.7930/J0Z31WJ2

NOAA. (2018). NOAA National Centers for Environmental Information, state of the climate: National climate report for annual 2017, published online January 2018. Retrieved from https://www.ncdc.noaa.gov/ sotc/national/201713

Oliva, R., Daganzo, E., Richaume, P., Kerr, Y., Cabot, F., Soldo, Y., ... Lopes, G. (2016). Status of Radio Frequency Interference (RFI) in the 1400$1427 \mathrm{MHz}$ passive band based on six years of SMOS mission. Remote Sensing of Environment, 180, 64-75. https://doi.org/10.1016/j.rse. 2016.01.013

Papagiannopoulou, C., Miralles, D. G., Dorigo, W. A., Verhoest, N. E. C., Depoorter, M., \& Waegeman, W. (2017). Vegetation anomalies caused by antecedent precipitation in most of the world. Environmental Research Letters, 12, 074016. https://doi.org/10.1088/1748-9326/aa7145

Pei, F., Wu, C., Liu, X., Li, X., Yang, K., Zhou, Y., ... Xia, G. (2018). Monitoring the vegetation activity in China using vegetation health indices. Agricultural and Forest Meteorology, 248, 215-227. https:// doi.org/10.1016/j.agrformet.2017.10.001

Piao, S., Wang, X., Wang, K., Li, X., Bastos, A., Canadell, J. G., ... Sitch, S. (2020). Interannual variation of terrestrial carbon cycle: Issues and perspectives. Global Change Biology, 26(1), 300-318. https://doi. org/10.1111/gcb.14884

Reichstein, M., Bahn, M., Ciais, P., Frank, D., Mahecha, M. D., Seneviratne, S. I., ... Wattenbach, M. (2013). Climate extremes and the carbon cycle. Nature, 500, 287-295. https://doi.org/10.1038/ nature 12350

Reichstein, M., Falge, E., Baldocchi, D., Papale, D., Aubinet, M., Berbigier, P., ... Valentini, R. (2005). On the separation of net ecosystem exchange into assimilation and ecosystem respiration: Review and improved algorithm. Global Change Biology, 11, 1424-1439. https://doi. org/10.1111/j.1365-2486.2005.001002.x

Robinson, N. P., Allred, B. W., Smith, W. K., Jones, M. O., Moreno, A., Erickson, T. A., ... Running, S. W. (2018). Terrestrial primary production for the conterminous United States derived from Landsat $30 \mathrm{~m}$ and MODIS $250 \mathrm{~m}$. Remote Sensing in Ecology and Conserveration, 4, 264-280. https://doi.org/10.1002/rse2.74

Rodríguez-Fernández, N. J., Mialon, A., Mermoz, S., Bouvet, A., Richaume, P., Al Bitar, A., ... Wigneron, J. -P. (2018). An evaluation of SMOS L-band vegetation optical depth (L-VOD) data sets: High sensitivity of L-VOD to above-ground biomass in Africa. Biogeosciences, 15, 4627-4645. https://doi.org/10.5194/bg-15-4627-2018

Ryu, Y., Baldocchi, D. D., Kobayashi, H., Van Ingen, C., Li, J., Black, T. A., ... Roupsard, O. (2011). Integration of MODIS land and atmosphere products with a coupled-process model to estimate gross primary productivity and evapotranspiration from $1 \mathrm{~km}$ to global scales. Global Biogeochemical Cycles, 25(4). https://doi.org/10.1029/2011G B004053

Saatchi, S. S., Harris, N. L., Brown, S., Lefsky, M., Mitchard, E. T. A., Salas, W., ... Morel, A. (2011). Benchmark map of forest carbon stocks in tropical regions across three continents. Proceedings of the National Academy of Sciences of the United States of America, 108, 9899-9904. https://doi.org/10.1073/pnas.1019576108 
Sala, O. E., Gherardi Laureano, A., Reichmann, L., Jobbágy, E., \& Peters, D. (2012). Legacies of precipitation fluctuations on primary production: Theory and data synthesis. Philosophical Transactions of the Royal Society B: Biological Sciences, 367(1606), 3135-3144. https:// doi.org/10.1098/rstb.2011.0347

Sims, D. A., Brzostek, E. R., Rahman, A. F., Dragoni, D., \& Phillips, R. P. (2014). An improved approach for remotely sensing water stress impacts on forest C uptake. Global Change Biology, 20, 2856-2866. https://doi.org/10.1111/gcb.12537

Sitch, S., Friedlingstein, P., Gruber, N., Jones, S. D., Murray-Tortarolo, G., Ahlström, A., ... Myneni, R. (2015). Recent trends and drivers of regional sources and sinks of carbon dioxide. Biogeosciences, 12(3), 653-679. https://doi.org/10.5194/bg-12-653-2015

Sitch, S., Huntingford, C., Gedney, N., Levy, P. E., Lomas, M., Piao, S. L., ... Woodward, F. I. (2008). Evaluation of the terrestrial carbon cycle, future plant geography and climate-carbon cycle feedbacks using five Dynamic Global Vegetation Models (DGVMs). Global Change Biology, 14(9), 2015-2039. https://doi. org/10.1111/j.1365-2486.2008.01626.x

Smith, M. D. (2011). An ecological perspective on extreme climatic events: A synthetic definition and framework to guide future research. Journal of Ecology, 99(3), 656-663. https://doi. org/10.1111/j.1365-2745.2011.01798.x

Stocker, B. D., Zscheischler, J., Keenan, T. F., Prentice, I. C. Seneviratne, S. I., \& Peñuelas, J. (2019). Drought impacts on terrestrial primary production underestimated by satellite monitoring. Nature Geoscience, 12, 264-270. https://doi.org/10.1038/s4156 1-019-0318-6

Tramontana, G., Jung, M., Schwalm, C. R., Ichii, K., Camps-Valls, G., Ráduly, B., ... Papale, D. (2016). Predicting carbon dioxide and energy fluxes across global FLUXNET sites with regression algorithms. Biogeosciences, 13, 4291-4313. https://doi.org/10.5194/ bg-13-4291-2016

Unger, S., \& Jongen, M. (2015). Consequences of changing precipitation patterns for ecosystem functioning in grasslands: A review. Progress in Botany, 347-393. https://doi.org/10.1007/978-3-31908807-5 14

U.S. Geological Survey. (2011). 20141010, NLCD 2011 Land Cover (2011 Edition, amended 2014). National Geospatial Data Asset (NGDA) Land Use Land Cover: U.S. Geological Survey.

Vicente-Serrano, S. M., Gouveia, C., Camarero, J. J., Begueria, S., Trigo, R., Lopez-Moreno, J. I., ... Sanchez-Lorenzo, A. (2013). Response of vegetation to drought time-scales across global land biomes. Proceedings of the National Academy of Sciences of the United States of America, 110(1), 52-57. https://doi.org/10.1073/pnas.12070 68110

Wang, H., Prentice, I. C., Keenan, T. F., Davis, T. W., Wright, I. J., Cornwell, W. K., ... Peng, C. (2017). Towards a universal model for carbon dioxide uptake by plants. Nature Plants, 3, 734-741. https://doi. org/10.1038/s41477-017-0006-8

Wang, T., Liu, D., Piao, S., Wang, Y., Wang, X., Guo, H., ... Zhao, Y. (2018). Emerging negative impact of warming on summer carbon uptake in northern ecosystems. Nature Communications, 9(1). https://doi. org/10.1038/s41467-018-07813-7

Wickham, J., Homer, C., Vogelmann, J., McKerrow, A., Mueller, R., Herold, N., \& Coulston, J. (2014). The Multi-Resolution Land Characteristics (MRLC) Consortium - 20 years of development and integration of USA national land cover data. Remote Sensing, 6, 7424-7441. https:// doi.org/10.3390/rs6087424

Wigneron, J. P., Fan, L., Ciais, P., Bastos, A., Brandt, M., Chave, J., ... Fensholt, R. (2020). Tropical forests did not recover from the strong 2015-2016 El Niño event. Science Advances, 6(6), 2015-2016. https://doi.org/10.1126/sciadv.aay4603
Wigneron, J. P., Kerr, Y., Waldteufel, P., Saleh, K., Escorihuela, M. J., Richaume, P., ... Schwank, M. (2007). L-band Microwave Emission of the Biosphere (L-MEB) model: Description and calibration against experimental data sets over crop fields. Remote Sensing of Environment, 107, 639-655. https://doi.org/10.1016/ j.rse.2006.10.014

Wilcox, K. R., Shi, Z., Gherardi, L. A., Lemoine, N. P., Koerner, S. E., Hoover, D. L., ... Luo, Y. (2017). Asymmetric responses of primary productivity to precipitation extremes: A synthesis of grassland precipitation manipulation experiments. Global Change Biology, 23, 4376-4385. https://doi.org/10.1111/gcb.13706

Williams, A. P., Cook, E. R., Smerdon, J. E., Cook, B. I., Abatzoglou, J. T., Bolles, K., ... Livneh, B. (2020). Large contribution from anthropogenic warming to an emerging North American megadrought. Science, 368(6488), 314-318. https://doi.org/10.1126/scien ce.aaz 9600

Winkler, D. E., Belnap, J., Hoover, D., Reed, S. C., \& Duniway, M. C. (2019). Shrub persistence and increased grass mortality in response to drought in dryland systems. Global Change Biology, 25(9), 31213135. https://doi.org/10.1111/gcb.14667

Wolf, S., Keenan, T. F., Fisher, J. B., Baldocchi, D. D., Desai, A. R., Richardson, A. D., ... van der Laan-Luijkx, I. T. (2016). Warm spring reduced carbon cycle impact of the 2012 US summer drought. Proceedings of the National Academy of Sciences of the United States of America, 113, 5880-5885. https://doi.org/10.1073/pnas.15196 20113

Wu, D., Ciais, P., Viovy, N., Knapp, A. K., Wilcox, K., Bahn, M., ... Piao, S. (2018). Asymmetric responses of primary productivity to altered precipitation simulated by ecosystem models across three longterm grassland sites. Biogeosciences, 15, 3421-3437. https://doi. org/10.5194/bg-15-3421-2018

Wu, Z., Dijkstra, P., Koch, G. W., Peñuelas, J., \& Hungate, B. A. (2011). Responses of terrestrial ecosystems to temperature and precipitation change: A meta-analysis of experimental manipulation. Global Change Biology, 17(2), 927-942. https://doi. org/10.1111/j.1365-2486.2010.02302.x

Xie, P., Chen, M., Yang, S., Yatagai, A., Hayasaka, T., Fukushima, Y., \& Liu, C. (2007). A gauge-based analysis of daily precipitation over East Asia. Journal of Hydrometeorology, 8, 607-626. https://doi. org/10.1175/jhm583.1

Yang, Y., Fang, J., Ma, W., \& Wang, W. (2008). Relationship between variability in aboveground net primary production and precipitation in global grasslands. Geophysical Research Letters, 35(23). https://doi. org/10.1029/2008GL035408

Zhao, M., Heinsch, F. A., Nemani, R. R., \& Running, S. W. (2005). Improvements of the MODIS terrestrial gross and net primary production global data set. Remote Sensing of Environment, 95, 164-176. https://doi.org/10.1016/j.rse.2004.12.011

\section{SUPPORTING INFORMATION}

Additional supporting information may be found online in the Supporting Information section.

How to cite this article: Al-Yaari A, Wigneron J-P, Ciais $\mathrm{P}$, et al. Asymmetric responses of ecosystem productivity to rainfall anomalies vary inversely with mean annual rainfall over the conterminous United States. Glob. Change Biol.2020;00:1-15. https://doi.org/10.1111/gcb.15345 